\title{
Buchu - The Multi-Purpose Ethnomedicinally Important Specie and Its Benefits in the Reproductive System
}

\author{
Bongekile Skosana, Guillaume Aboua and \\ Stefan S du Plessis \\ Additional information is available at the end of the chapter \\ http://dx.doi.org/10.5772/57233
}

\section{Introduction}

Indigenous to the Cape region of South Africa [1], Buchu is an aromatic plant known for its essential-oil producing ability and its multiple healing properties. Known taxonomically as Agathosma betulina and Agathosma crenulata [1], its traditional benefits have made their way from Africa to the Western world.

The word "Buchu" originated from the Khoi-San people of southern Africa, and was a word used in reference to any plant that could be dried or powdered [2]. Nowadays, the name Buchu refers to the abovementioned Agathosma species. Previously known as Barosma betulia, the name originates from the word Barosma (Greek) meaning "heavy smell" and the word betulina (Latin) which means "birch-like", a word used in reference to the serrated birch-like appearance of the leaves [3].

There are 150 Agathosma species that are indigenous to South Africa, and of these, A. betulina and A. crenulata are the more renowned herbs [4]. These are used internationally and locally for a variety of medicinal purposes.

Agathosma betulina is a shrub that is well adapted to grow in dry regions [1]. The leaves have round oil glands found scattered across the leaf, which release an aromatic golden oil with a sweet peppermint-like odour [2]. Agathosma crenulata is an aromatic, single-stemmed shrub, which can be found growing in the mountainous regions of the Western Cape [5]. Its dark green leaves release a pale oil with sharp pulegone tones [2].

Fractionation of Buchu by distillation, crystallisation and chromatography releases an oil with many constituents [6]. Agathosma betulina contains the major volatile compounds limonene, 
menthone, diosphenol and one of its isomers $(\psi)$-diosphenol, and $l$-pulegone [7]. Aganthosma crenulata contains the same main constistuents, but has trace amounts of diosphenol and larger amounts of l-pulegone [7]. These are responsible for the odour, flavour and medicinal properties of Buchu oil [8]. Two monoterpene thiols are accountable for the distinguishing odour of Buchu oil, one being 9-mercapto-p-menthan-3-one [6]. This sulphur-containing terpene is essential to the aroma and flavour of the plant [6].

True to its description of being a multi-purpose specie, Buchu has long been used as an antiseptic, an anti-inflammatory agent, for urinary problems including maladies such as haematuria, calculi, kidney disease and infections of the bladder, prostate and urethra [9]. Today it is also used to stimulate perspiration in rheumatic disease and gout, as a digestive tonic [9] which treats cholera and stomach complaints, an antispasmodic, an antipyretic, as a treatment for colds and flu, and most importantly, as a diuretic. In current Pharmacopoeias, it is listed as a diuretic and a urinary tract antiseptic [2]. It is also listed as a treatment for arthritis, cellulite, nausea and diarrhoea, flatulence, prostatitis and UTI's [1, 2, 9].

A number of Buchu preparations are used to deliver it to the body. It may be prepared as a brandy, a tincture (an alcohol or aqueous solution), a tea, or soaked in vinegar [9]. The vinegar can be used for external applications to treat bruises, contusions, sprains and fractures, to clean wounds and to treat rheumatism [10]. The Khoi-San used the plant as an 'antibiotic repellent' to repel insects and mixed it with oil to use as a moisturiser, which was essential in their natural environment and desert climate surroundings [9]. Topical application allowed entry of the active ingredients of Buchu oil through the skin and provided antibacterial and antifungal properties, and also acted as an insect repellent and deodarant [9].

Buchu has a long-standing traditional use, but it has made its way into the fragrance and flavour industries due to its sulphur-containing compounds and sensory properties [2]. It is used to enhance fruit flavours and fragrances, and boost blackcurrant-like flavours. It has a naturally minty, sweet berry, apricot, peach and green herbal taste, and its oils are used in perfumes and colognes [2].

The list of ailments Buchu is capable of counteracting and the multitude of its historical and current uses are what help to define it as an ethnomedicinally important product, making it an outstanding phytomedicine and natural product to stave off illnesses (see Table 1).

\section{Pharmacological activity}

\subsection{Diuretic activity}

Diospenol is responsible for the diuretic action of Buchu [3]. There is no explanation of the mechanism of action, but the available literature states that diosphenol acts by irritating the gallbladder, causing the production of urine [18]. Buchu also contains flavonoids that induce urine production [11]. 


\subsection{Antimicrobial activity}

Buchu essential oils and extracts were analysed to assess the antimicrobial activity of the plant. The essential oils and extracts were found to be active against the selected pathogens, namely Staphylococcus aureus, Bacillus cereus, Klebsiella pneumonia and Candida albicans [12, 13]. Buchu extracts have a good antibacterial activity, and has been found to be more active against gram positive than gram negative bacteria $[12,13]$. Buchu was found to affect the development of biofilms by preventing attachment of bacteria to the polyvinyl chloride surface ${ }^{2}$. This was, however, not the case with the fungus (C. albicans), as exposure to the extracts improved the attachment to the surface, allowing the formation of a biofilm [2]. The more well known Buchu species are thus effective against bacteria, but not against fungi. There is, however, a less extensively researched member of the Agathosma family called A. arida that is effective against Candida albicans [1]. Agathosma species have been found to contain coumarins, phenolic substances with benzene and $\alpha$-pyrone rings [14]. A number of these compounds have been found to be active against microbials by stimulating macrophages, allowing the plant to have an indirect ability to eliminate infection [14].

\subsection{Anti-oxidant activity}

Free radicals are molecules with one or more unpaired electron(s) [15] that are highly reactive, attacking nearby stable molecules to gain an electron. The two forms of free radicals are reactive oxygen species (ROS) and reactive nitrogen species (RNS) [15]. Free radical scavengers are known as antioxidants, and these assist in keeping free radicals at physiologically homeostatic levels [15]. Polyphenolics in plants are scavengers of free radicals, allowing them to act as antioxidants [16]. These compounds act via several mechanisms to reduce free radicals, and make wonderful antioxidants due to the hydrogen donating ability of the phenolic groups [16]. Members of the Agathosma specie have been found to contain flavonoids such as diosmin, hesperidin,rutin, quercitin, mucilage and resins which have extensive anti-oxidant properties $^{1}$. These are some of the compounds that give the Buchu plant its anti-oxidant ability, allowing it to be effective against many ailments that result from an increase in oxidative stress.

\subsection{Anti-inflammatory activity}

Buchu oil contains limonene, a monoterpene hydrocarbon with anti-inflammatory properties $[12,13]$. Essential oils found in Agathosma have been found to inhibit the synthesis of leukotrienes by blocking synthesis of the key enzyme 5-lypoxygenase. By doing so, it reduces inflammation by preventing the initiation and maintenance of the inflammatory process, thereby limiting an infection and preventing its progression [2]. Limonene has also shown to be effective in reducing cyclooxygenase 1 and 2 biosynthesis [2], reducing the proinflammatory agents prostaglandins and leukotrienes from being synthesised, reducing inflammation.

\subsection{Toxicity}

The Buchu plant should be used at low dosages for most purposes as it contains diosphenol, a compound known to be toxic at higher doses [1]. Pulegone, another compound found in 
Buchu, is hepatotoxic [2]. It has been found to reduce the levels of glutathione, a substance used by the liver in several detoxification steps [2], which would allow the accumulation of toxins within the liver. The depletion of glutathione and the excess amounts of pulegone found at high dosages lead to hepatocellular necrosis. Care should thus be taken when Buchu is consumed to ensure that the maximal therapeutic benefits are acquired, without any of the unwanted toxic effects.

\section{Buchu and the reproductive system}

The benefits of Buchu may be applied to treat ailments of the reproductive system. As previously sited, Buchu is used as a urinary tract antiseptic and as an anti-inflammatory agent [2], thereby reducing the inflammation seen in UTI's and treating infections of the urethra and prostate. Buchu has many direct and indirect effects on the reproductive system via its ability to act as a diuretic, an anti-oxidant, anti-microbial and an anti-inflammatory agent. The ability of Buchu to do this will be looked at in more detail below, focussing on its actions in Benign Prostatic Hypertrophy/Hyperplasia (BPH), prostatitis, in UTI's and on male fertility.

\subsection{Benign prostatic hypertrophy/hyperplasia}

$\mathrm{BPH}$ is the non-malignant enlargement of the prostate, and is the most common benign tumour in men over the age of 60 [17]. BPH has many predisposing factors, which include age, ethnicity, medical and family history and lifestyle factors such as cigarette smoking [17]. Men who have suffered from chronic diseases such as hypertension, coronary artery disease and diabetes mellitus are at risk of developing $\mathrm{BPH}$ [17].

The prostate is an exocrine gland [18] composed of fibromuscular tissue in a network of glands embedded in stroma [19]. Androgens are essential to growth of the prostate during early development, purberty and aging [20]. Androgens do not essentially cause BPH, but have been found to play a role in hypertrophy of the prostate along with other factors such as aging, diet, an increase in inflammatory mediators, hormones and oxidative stress [19].

$\mathrm{BPH}$ is characterised by nodular overgrowth of the epithelium and fibromuscular tissue [18] of the prostate, with the differentiation of fibroblasts into myofibroblasts being the hallmark of tissue remodelling [18] in the disease. Increased deposition of collagen in the ultrastruscture of the penis and the loss of smooth muscle causes urethral obstruction [21], causing a list of clinical symptoms related to urinary tract obstruction.

The pathophysiology of $\mathrm{BPH}$ is multifaceted, with local and endocrine factors being involved [17]. One of the main instigators is age-related changes to sex steroid hormone levels which leads to alterations in the metabolism of androgens locally. This disrupts the growth factor signalling pathways which interact with the stroma/epithelium, promoting tissue remodelling, leading to an increase in the size of the prostate [17]. The remodelled epithelium has an altered production of cytokines and chemoattractants, which encourages inflammation of the prostate and the production of ROS and RNS. With the increased proliferation of stromal and fibro- 
muscular cells comes an increased demand of nutrition and oxygen to be delivered to the prostate [17]. This leads to local tissue hypoxia, promoting neovascularisation to cope with the increased demand for blood flow, and the production of ROS [17]. The increase in ROS leads to further fibroblast to myofibroblast differentiation, perpetuating the cell proliferation cycle and resulting in a further increase in prostate volume.

The roles of other steroidal hormones [20] have been proposed in the pathophysiology of BPH. The reason for this stemmed from the finding that prostatic cells continue to grow, even in the face of declining androgen levels [23]. This led to the rationale that other factors being secreted by the testes may stimulate growth or even sensitize cells of the prostate to the actions of androgens [23]. As men age, the increase in their body weight increases the amount of adipose tissue within the body, leading to an increase in circulating oestrogen levels [24]. This is evident in the levels of free estradiol found circulating in the bloodstream, which remains constant due to the age-related increases in body weight $[25,26]$. Adipose tissue causes increased secretion of the enzyme aromatase, which stimulates the conversion of androgen to oestrogen. Increased circulating oestrogen levels stimulate the increased proliferation of cells seen in BPH as oestrogens have been found to increase the number of prostatic epithelial and stromal cells [27, 29]. Oestrogen also has an indirect effect on the increase in prostate volume through its role in mediating the alterations in other circulating serum hormones [20].

The changes seen in androgen levels with age disrupt the interaction of growth factors with prostate cells [22]. The growth of prostate cells is enhanced by the production of growth factors, which are supplied to the prostate via circulation [17] or locally through autocrine production by stromal cells [18]. The locally produced growth factors control cell differentiation and proliferation, and matrix protein production through a network that is interactive, providing for a negative feedback control mechanism that controls normal cell growth [18]. Any disruption in this network leads to abnormal proliferation and stromal hyperplasia [18], which manifects as BPH. Stromal cell proliferation is enhanced by fibroblast growth factors (FGF 1 and 9), insulin-like growth factors (IGF I and II) and transforming growth factor $\beta$ (TGF $\beta 1$ ) [18]. Expression of these growth factors is upregulated in $\mathrm{BPH}$ and are a mechanism which may be altered to reduce accumulation of prostatic cells.

The prostate is located at the neck of the bladder, enveloping the urethra [17]. This location plays a role in the obstructive symptoms seen in patients with $\mathrm{BPH}$, which also correlate with the size of the prostate [17]. There are two components of prostatic enlargement that play a role in obstruction of the bladder outlet which lead to lower urinary tract symptoms, namely static and dynamic [17].

The static component is related to enlargement of the prostate which is attributed to the nodular proliferation classically seen in benign prostatic hypertrophy and hyperplasia [17]. This component accounts for the symptoms related to obstruction of the lower urinary tract seen in cases of BPH. The dynamic component related to the tone of prostatic smooth muscle [17]. Smooth muscle accounts for a rather large percentage of prostatic volume in BPH [17]. These provide binding sites for $\alpha_{1}$-adrenoreceptors, making the prostate susceptible to changes in adrenoreceptor signalling. $\alpha$-adrenergic signalling has a significant influence on survival of stromal cells of the prostate and on the activity of smooth muscle cells in the prostate and the 
rest of the body [17]. $\alpha$-adrenergic signalling alters expression of TGF $\beta 1$ and extracellular matix turnover [18].

$\mathrm{BPH}$ presents clinically with lower urinary tract symptoms such as frequent urination, nocturia (frequent urination at night), the feeling of a full bladder even after voiding, post urination dribbling, weak urine stream and difficulty initiating urination [30]. It is associated with serious morbidity and may lead to complications which include acute urinary retention, and a reduction in the quality of life [17].

\subsection{Inflammation in $\mathrm{BPH}$}

A substantial number of inflammatory cells and pro-inflammatory cytokines have been found to be involved in prostatic cell proliferation [19]. The prostate is generally populated by a small amount of T and B lymphocytes, mast cells and macrophages [19]. These are chronically activated in $\mathrm{BPH}$ and release pro-inflammatory cytokines such as Interleuken 2( IL-2), Interferon gamma (IFN- $\gamma$ ) and TGF $\beta$, which stimulate growth of the fibromuscular stroma [19]. Cytokines released by neighbouring cells stimulate the release of cyclo-oxygenase 2 (COX-2) in prostatic epithelial cells, increasing the cell turnover within the prostate [31, 32].

The local hypoxia stimulated by high cell turnover in BPH brings about the release of ROS which act as inflammatory mediators, causing enlargement of the prostate via stimulating differentiation of fibroblasts to myofibroblasts [33]. Local hypoxia also stimulates the release of growth factors and cytokines by stromal cells, including IL-8, vascular endothelial growth factors, fibroblast growth factors (FGF-2 and 7) and TGF $\beta$ [19]. TGF $\beta$ regulates stromal cell proliferation and differentiation in $\mathrm{BPH}$, and is a key factor in the control of prostatic growth by androgens [34].

The prostate gland's immune response is mainly a cell mediated one, with regulatory $\mathrm{T}$ cells found in the stromal tissue and cytotoxic T cells in the gland's epithelia [35]. The accumulation of activated lymphocytes seen in inflammation of the prostate contributes to the development of BPH by causing tissue destruction and subsequent tissue rebuilding [20]. The cytokines produced may drive growth factor production leading to angiogenesis and cell proliferation as a "wound healing" mechanism [20]. The damage induced by inflammation of the prostate is thus a chronic process of wound healing where the excessive proliferation of prostatic cells leads to a cyclic reactivation of inflammation within the prostate [20]. This hyperproliferation and wound healing leads to the formation of prostatic nodules seen in benign prostatic hypertrophy/hyperplasia [19]. Inflammation leads to prostatic enlargement by stimulating growth of the prostate directly or indirectly by reducing apoptosis [19].

Whilst the mechanism of how inflammation leads to the pathogenesis of BPH is well understood, the origin of the inflammation is not as clearly understood [19]. Numerous aetiologies have been brought forward, including bacterial infections, an autoimmune response, urine reflux combined with chemical inflammation, hormones, diet and any combination of these [19]. The origin thus seems to be multifactorial [19]. It has been proposed that constant injury to epithelial cells leads to the loss of its function as an effective barrier, facilitating the passage 
and growth of infectious agents, which ultimately leads to further stimulation of the inflammatory response [19].

Inflammation of the prostate increases the risk of urinary retention, which suggests that the inflammatory processes occurring in BPH lead to lower urinary tract symptoms [19].

Prostatic inflammation is a possible target for the prevention and treatment of BPH. Phytotherapy has become a popular treatment modality for $\mathrm{BPH}$, and the anti-inflammatory properties of Buchu may be applied to help alleviate inflammation found in BPH. The presence of essential oils and limonene in buchu oil can inhibit the synthesis of leukotrienes by blocking synthesis of the enzyme 5-LOX ${ }^{2}$. This will reduce inflammation by preventing the initiation and maintenance of inflammatory processes, thereby limiting an infection and preventing its progression ${ }^{2}$. Buchu can also prevent the attachment of bacteria to internal surfaces, inhibiting biofilm formation ${ }^{2}$. The flavonoids found in buchu may also modulate of inflammation and strengthen connective tissue, reducing inflammation and any downstream effects that it may have. The reduction in inflammation can assist in reducing inflammation-induced damage seen in prostatic tissue, putting an end to chronic would healing that is activated to repair the cells damaged by inflammatory processes. It will also diminish inflammation-based tissue remodelling and prevent further enlargement of the prostate.

\subsection{Oxidative stress in $\mathrm{BPH}$}

Oxidative stress is a condition caused by the imbalance between free radicals and free radical scavengers [15]. Free radicals are molecules with one or more unpaired electron(s) [36] that are highly reactive, attacking nearby stable molecules to gain an electron [15]. The molecule from which the electron was acquired becomes damaged, and it itself may initiate events that lead to damage of surrounding cells [37]. Free radicals are present at physiological concentrations which help maintain homeostasis via their actions as signal transducers [38]. Free radicals come in two common forms, i.e. ROS and RNS [15]. ROS include the superoxide ion, hydrogen peroxide, the peroxyl and the hydroxyl radical [39]. Reactive nitrogen species include nitric oxide, nitrous oxide, peroxynitrite, peroxynitrous acid and the nitroxyl anion, and are considered to be a subsection of ROS [39]. Free radical scavengers are known as antioxidants, and these assist in keeping free radicals at physiologically homeostatic levels [15]. By doing this, they help to prevent any pathological effects that may be activated by the development of oxidative stress, where ROS exceed the number of antioxidants due to increased ROS, decreased levels of antioxidants, or both [15].

The body produces ROS on a daily basis via metabolic processes that occur in a normal cell [40]. ROS are generated endogenously by mitochondria and through metabolic and inflammatory processes, but are also introduced into the body via external sources [40]. Physiological levels of ROS are essential to the regulation of many biological processes [40]. Increased generation of ROS is related to tissue injury and DNA damage, which are processes found in cellular proliferation, aging, infections and mutations in mitochondrial DNA [40]. Increased levels of ROS have also been associated with neoplastic transformation, abnormal cell proliferation and growth [40]. 
Androgens have been found to increase oxidative stress in the prostate gland [41]. Pathological levels of ROS bring about lipid peroxidation, apoptosis and DNA damage [15]. Lipid peroxidation is one of the main signs of oxidative damage, and has been found to stimulate alterations in membrane structure and has been linked to enzyme inactivation [41]. ROS cause this by abstracting a hydrogen atom from side chains of fatty acids in the cell membrane, initiating lipid peroxidation which has been found to enhance carcinigenesis [41].

Intracellular changes in the levels of ROS occur during proliferative, apoptotic and senescent processes, which can lead to the activation of signalling pathways [40]. As mentioned previously, changes in tissue oxygenation during these processes causes and upregulation of cytokines and growth factors, which trigger prostatic cell proliferation, prostatic growth and inflammation. These processes themselves are a source of oxidative stress, which then leads to further proliferation and the initiation a chronic inflammation. The presence of ROS is thus an essential component in the pathogenesis of BPH when present at high levels within the prostate. This will help reduce ROS levels to physiologically homeostatic levels, allowing them to carry out their functions as signal transducers without activating any pathological mechanisms.

Endogenous antioxidant levels decrease with age [42], and this is compounded by other agerelated changes which ultimately lead to the manifestation of BPH. Oxidative stress can lead to cell mutations, which may lead to carcinogenesis and remodelling of the gland's internal structure [43]. BPH is an alternative, benign pathway of unregulated prostatic growth which is encouraged by inflammatory mediators and increased oxidative stress [41]. Management of oxidative stress is thus an imperative step in the management of $\mathrm{BPH}$ [41].

Management of oxidative stress is also an important factor in the prevention and treatment of $\mathrm{BPH}$ [41]. Buchu is an antioxidant-rich natural remedy that may be used to reduce oxidative stress. The polyphenolics contained within the plant scavenge free radicals, allowing them to act as anti-oxidants ${ }^{1}$. The hydrogen donating ability of the phenolic groups ${ }^{1}$ will help reduce the bulid up of ROS. By donating hydrogen groups, these polyphenolics will stabilise free radicals, preventing them from attacking nearby cells to acquire it.

An increase in free radicals stimulates cyclooxygenase(COX) [44], a key enzyme in initiantion of the inflammatory process. Increase COX activity stimulates the production of an array of pro-inflammatory substances called prostaglandins. In patients with $\mathrm{BPH}$ and prostatitis there is an increased production of cyclooxygenase 2 (COX-2) and a reduction in the levels of prostaglandin $\mathrm{E}_{1}$ [44]. Free radical scavengers, particularly hydroxyl radical scavengers, suppress the over expression of COX and prostaglandin synthesis [44]. Ethanolis extracts of Buchu (Agathosma betulina) possess an inhibitory effect on COX-2 synthesis [44]. This inhibition will, as a consequence, suppress the inflammatory response and reduce hypertrophy/hyperplasia and inflammation of the prostate, which is the goal of antioxidant treatment.

Reducing levels of ROS allows Buchu to interrupt the pathogenesis of BPH by reducing tissue injury, DNA damage, neoplastic transformation, and activation of growth factors that lead to abnormal cell proliferation and growth [40]. A diet rich in antioxidants such as vitamins A, C and $\mathrm{E}$ may also be prescribed to work in unison with Buchu to reduce oxidative stress. 


\section{Urinary tract infections}

UTI's have a varied incidence that is dependent on age, sex and predisposing factors [45]. UTI's are an uncommon occurrence in healthy young men, but incidence does increase with an increase in age due to predisposing factors and urological abnormalities [45].

The most common cause of UTI'sare bacteria, the most common being Escherichia coli, Klebsiella pneumonia, enterococci and Staphylococcus epidermidis, to name a few [45]. Bacteria causing UTI'sin men have been found to reach the urinary tract via an ascending route [45]. The bacterial flora found around the region of the anus is a reservoir for potential pathogens of the urinary tract [45]. Invasion of the urinary tract is lead by colonisation of the opening of the urethra, followed by adhesion and attachment to the epithelial lining of the urethra, with growth of bacteria on the urethral surface leading to ascension of bacteria into the urinary tract [45]. Invasion of the urethra by bacteria is difficult in men due to the distance between the opening of the urethra and the perianal region where the bacteria causing UTI'sare known to reside, the length of the urethra and the presence of prostatic fluid in the urethra, which is known to have bactericidal activity [45].

Co-infection of the prostate in patients with UTI'sis unknown [45], but a mechanism has been suggested. Reflux of urine into ducts of the prostate lead to the retrograde transfer of bacteria from the urethra into the prostate, bringing about infection of the prostate gland (bacterial prostatitis) [46].

Men with UTI'sare usually predisposed to them by functional or structural abnormalities [47, 49]. Lesions of the urinary tract which predispose men to UTI'sinclude bladder outlet obstruction, bladder stones, stricture of the urethra, cancer of the bladder and kidney stones [50].

Signs and symptoms of UTI'sinclude frequency, pain on urination, flank pain and/or costovertebral angle tenderness, which is tenderness in the area overlying the kidney [45].

Lower UTI'sare related to erectile dysfunction and BPH [51]. This interaction may be affected by extraneous variables such as diabetes, aging and coronary artery diseases such as atherosclerosis, but it was found to be independent of these variables when the co-morbidities were controlled for [51]; the association between lower UTI's(UTI) and erectile dysfunction remains. Men who are found to have more severe lower UTI's have more severe erectile dysfunction [51]. The mechanism that gives rise to this interaction is obstruction of the urethra which is propagated by collagen deposition in the penile ultrastructure and the subsequent loss of smooth muscle [ ${ }^{2}$. The loss of smooth muscle leads to the reduction in erectile tissue, resulting in erectile dysfunction.

Buchu has been found to have antimicrobial activity against bacteria that cause urinary tract infections, i.e. Staphylococcus aureus and Klebsiella pneumonia.

Flavonoids found in buchu may modulate inflammation and strengthen connective tissue. They may be used in the acute and long-term use for chronic or recurrent UTI, reducing the symptoms caused by UTI's [52]. The diuretic actions of Buchu will also assist in the reduction of inflammation by helping to flush bacteria out of the urinary tract through its ability to 
increase urinary output [52], serving to reduce colonisation of the urethra by bacteria, reducing the duration of the UTI.

Buchu may be used in the form of a herbal tincture or a herbal tea. The tincture will deliver adequate quantities of the herb allowing its actions to be distributed throughout the body. The tea will support the herbal action of the tincture and simultaneously increase fluid intake [52].

Buchu may be used alone or in combination with other plants. In combination, the synergistic interactions of the extracts found in buchu and those of other plants will produce a better therapeutic effect in the treatment of a variety of ailments, or, in this instance, in the treatment of UTI's[44]. Antibiotic resistance is rife, and is the cause of a prolonged disease course. A combination of antimicrobial agents helps prevent resistance to antibiotics, increases the spectrum of activity and may even reduce the side effects of therapy [44]. A combination of the plants Agathosma crenulata, Dodonaea viscose and Eucalyptus globules produces a broad spectrum and enhanced antimicrobial activity [44]. Combination of these plants in a 1:1:1 ratio provides additive and synergistic effects [53] where the extracts of each plant act via multiple mechanisms to reduce the number of disease causing microbials. The mixture of bioactive constituents target numerous target sites and work in a synergistic manner [53]. The combination of these plants give an additive anti-inflammatory, anti-fungal, analgesic, antibacterial and antiviral effect $[54,55]$.

By preventing and reducing colonisation of the urinary tract that leads to urinary tract infections, other co-morbidities associated with UTI's such as erectile dysfunction, prostatitis and erectile dysfunction may be simultaneously prevented.

\section{Fertility and ROS}

Physiological levels of free radicals are essential in the regulation of sperm maturation, capacitation and hyperactivation, acrosome reaction and sperm-oocyte fusion [15]. ROS can make their way into the seminal plasma where they have a regulatory and a damaging an effect on spermatozoa. Leukocytes and immature spermatozoa are sources of ROS within the seminal plasma [15]. Leukocytes produce ROS as part of their mechanism to clear the body of infections [56], but during an infection, increased production and chemotaxis of leukocytes leads to an increase in ROS and a reduction in the antioxidant called superoxide dismutase [57]. This results in oxidative stress which has negative effects on the function of spermatozoa [15]. The changes in sperm parameters brought about are a reduction in motility and in the fertilisation capacity $[58,59]$. The presence of excess cytoplasm in immature spermatozoa leads to activation of the NADPH system, which donates electrons to free radicals [13], allowing them to build up within the seminal plasma. This excess of free radicals leads to an increase in ROS and the disadvantages thereof.

Exogenous sources of ROS allow pathological amounts of ROS to build up within the seminal plasma [15]. Environmental pollutants increase ROS in testes, causing oxidative stress, DNA damage and impaired sperm production [15]. Cigarette smoking allows nicotine to make its 
way into the seminal plasma, which has been associated with the production of free radicals and a decrease in antioxidant function [15]. Cigarette smoking also increases concentrations of leukocytes in seminal plasma [15]. Excessive intake of alcohol increases ROS while decreasing antioxidants due to increased ethanol metabolism [60]. Spinal cord injury is associated with higher levels of ROS and higher numbers of leukocytes, both of which are known to contribute to oxidative stress, leading to reduces sperm motility and poor sperm morphology [61, 62]. Dilatation of veins in the plexus surrounding the spermatic cord (varicocele) is associated with increased levels of ROS, with a concomitant decrease in sperm function [63]. Higher quantities of nitric oxide have also been found in men with varicocele, and these men have also been found to have higher markers of oxidative stress [64].

As previously stated, ROS have both physiological and pathological roles. Physiological levels of ROS have been found to play a vital role in normal sperm function [15]. ROS are signalling molecules in many processes which allow fertilisation [15]. ROS are essential in sperm maturation as they have been shown to stabilise sperm chromatin, which is required to maintain genetic integrity [15]. Capacitation, a process which occurs in the female genital tract, is a maturation process which gives sperm the ability to gain hyperactive motility and the potential to carry out an acrosome reaction [15]; both of which are vital for fertilisation to take place. Capacitation is a series of molecular changes that brings about membrane hyperpolarisation, protein phosphorylation and an increase in $\mathrm{pH}$ and cAMP [65]. Hyperactivation, a subsection of capacitaion, provide spermatozoa with the ability to move through cervical mucous and to penetrate cumulus cells of the oocyte [15]. The acrosome reaction, which is the release of proteolytic enzymes contained within the acrosomal cap, helps to degrade the extracellular matrix of the zona pellucida [65]. This allows spermatozoa to burrow through the zona pellucida, allowing penetration of this layer to permit fusion with the oocyte. Physiological levels of ROS are also essential for sperm-oocyte fusion [15]. Fluidity of the sperm membrane is required to fusion to take place [66]. This is acquired by spermatozoa through capacitation and acrosome reaction [15], processes which are both assisted by the presence of ROS. Membrane fluidity allows sperm to fuse with the oocyte, allowing successful fertilisation.

Pathological levels of ROS are detrimental to sperm function [15]. An imbalance between ROS and antioxidant defence mechanisms results in pathological processes to be initiated. ROS cause damage to proteins, lipid molecules and DNA [67]. Lipid peroxiation causes loss of fatty acids from sperm plasma membranes, which affects the structure and function (i.e. fluidity, transport processed, receptor transduction) of spermatozoa, impairing the functional parameters of sperm and their ability to fertilize [67, 68]. Sperm is usually resistant to DNA damage due to the tight packaging of DNA material and the innate antioxidant defense mechanisms in place [69]. ROS causes DNA damage and leads to infertility. Nitric oxide and hydrogen peroxide have been found to induce DNA damage, which brings about DNA fragmentation and reduced sperm parameters (i.e. motility, and morphology) [70, 73]. The impaired the ability of the Y chromosome to repair DNA strand breaks makes spermatozoa more vulnerable to DNA damage [74]. Damage to cellular components initiates apoptosis. Abnormal spermatozoa are regularly removed via program- 
med cell death, which is assisted by the presence of ROS [75]. ROS activate mitochondrial release of cytochrome c, which ultimately activates caspases which leads to apoptosis $[76,78]$. Hypochlorous acid is also known to oxidise cellular components, directly activating apoptosis [78]. Also, high temperatures within the male reproductive system have been correlated to higher levels of ROS [13].

Antioxidants have been explored as possible therapeutics that may lead to a reduction in levels of ROS [15]. Antioxidant therapy has been shown to reduce oxidative stress, resulting in reduced DNA damage and apoptosis. Antioxidants may be used to keep free radicals at levels that are appropriate for physiological function, while reducing the levels that bring about unwanted pathologies and infertility [15].

Buchu is well known for its antioxidant properties. As discussed above, it has been shown to contain factors which assist in the antioxidant activity of the plant. By using this plant in small therapeutic doses, Buchu may be effective in staving off excess build up of free radicals, decreasing the negative effects on the function of spermatozoa that lead to infertility.

\section{Conclusions}

Buchu has been utilised in southern Africa for millennia by the Khoi-San people indigenous to the region for a multitude of daily uses and a plethora of ailments. It is a renowned herb whose traditional benefits have made their way from Africa to the Western world. There are 150 Agathosma species that are indigenous to South Africa, and of these, Agathosma betulina and Agathosma crenulata are the most well known. True to its description of being a multi-purpose specie, Buchu has long been used as an antiseptic, and anti-inflammatory, for urinary problems including maladies such as haematuria, calculi, kidney disease and infections of the bladder, prostate and urethra. Buchu's pharmacological profile allows it to be used for its diuretic, antimicrobial, anti-inflammatory and antiseptic purposes. Its uses today have spread beyond its medicinal applications, as this compound has made its way into the fragrance and flavour industries where it is used to enhance fruit flavours and boost fragrances. Buchu's biological profile allows it to be used to alleviate ailments of the reproductive system. Its uses in inflammation, oxidative stress and in the removal of pathogenic species from the body have allowed it to be effective in treating disorders such as BPH and UTI's. Its antioxidant properties may be used to prevent infertility through its potential to help keep ROS/RNS at physiological levels, allowing them to regulate sperm function without allowing pathological levels to be obtained, which can have detrimental effects on the ability to reproduce. Whilst the advantages of using this natural product have been known for a substantial amount of time, the use of Buchu has not made its way into mainsteam markets as definitive research still needs to be done to substantiate its benefits. Because of all its benefits, it would be a worthy task to look into all its properties so that maximal benefit may be obtained from its use. 


\begin{tabular}{|c|c|c|}
\hline Author/Study & Findings/Uses of Buchu & Application/Mechanism of action \\
\hline Moolla et al, 2007 & \multirow{3}{*}{ Anti-oxidant properties } & Members of the Agathosma specie contain flavonoids, \\
\hline \multirow[b]{2}{*}{ Moolla and Viljoen, 2009} & & $\begin{array}{l}\text { i.e. diosmin, hesperidin, rutin, quercitin, mucilage and } \\
\text { resins with extensive anti-oxidant properties }\end{array}$ \\
\hline & & $\begin{array}{l}\text { These compounds act via several mechanisms to reduce } \\
\text { free radicals }\end{array}$ \\
\hline Cowan MM, 1999 & \multirow{5}{*}{$\begin{array}{c}\text { Antibacterial } \\
\text { Antimicrobial } \\
\text { Antifungal } \\
\text { Antibiotic repellent }\end{array}$} & Buchu essential oils and extracts active against selected \\
\hline Moolla et al, 2007 & & $\begin{array}{l}\text { pathogens, namely Staphylococcus aureus, Bacillus } \\
\text { cereus, Klebsiella pneumonia and Candida albicans. }\end{array}$ \\
\hline Lis-Balchin et al, 2001 & & \\
\hline Shwegler, 2003 & & Affects the development of biofilms by preventing \\
\hline Viljoen et al, 2007 & & $\begin{array}{l}\text { attachment of bacteria } \\
\text { Agathosma species found to contain coumarins, } \\
\text { phenolic substances with benzene and a-pyrone rings. A } \\
\text { number of these compounds have been found to be } \\
\text { active against microbials by stimulating macrophages }\end{array}$ \\
\hline Lis-Balchin et al, 2001 & Urinary problems & \\
\hline \multirow[t]{3}{*}{ Moolla and Viljoen, 2009} & $\begin{array}{l}\text { haematuria } \\
\text { calculi }\end{array}$ & $\begin{array}{l}\text { Oil distilled from Buchu leaves has therapeutic } \\
\text { properties and major uses, including the treatment of }\end{array}$ \\
\hline & kidney disease & kidney and urinary tract infections, as well as \\
\hline & $\begin{array}{l}\text { infections of the bladder, } \\
\text { prostate, urethra }\end{array}$ & haematuria and prostatitis \\
\hline \multicolumn{3}{|l|}{ Watt and Breyer- } \\
\hline Brandwijk, 1962 & \multirow{4}{*}{ Diuretic properties } & \multirow{4}{*}{$\begin{array}{l}\text { Diospenol is responsible for the diuretic action of Buchu. } \\
\text { Diosphenol acts by irritating the gallbladder, causing the } \\
\qquad \text { production of urine. } \\
\text { Buchu contains flavonoids that induce urine production }\end{array}$} \\
\hline Gentry HS, 1961 & & \\
\hline Eaton CL & & \\
\hline Simpson, 1988 & & \\
\hline Moolla et al, 2007 & \multirow{5}{*}{$\begin{array}{l}\text { Arthritis, Rheumatism } \\
\text { Nausea and diarrhoea } \\
\text { Flatulence }\end{array}$} & \multirow{5}{*}{$\begin{array}{l}\text { The Agathosma species has been many applications, } \\
\text { among these are its uses in the treatment of arthritis } \\
\text { and rheuamtism through its ability to reduce uric acid. } \\
\text { Buchu has been listed as a treatment for stomach } \\
\text { ailments and for relief from nausea, diarrhoea and } \\
\text { flatulence }\end{array}$} \\
\hline Moolla and Viljoen, 2009 & & \\
\hline Lis-Balchin M et al, 2001 & & \\
\hline Bajpayee P et al, 2012 & & \\
\hline 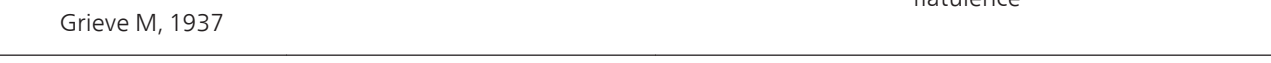 & & \\
\hline Grieve M, 1937 & & A number of Buchu preparations are used to deliver it to \\
\hline \multirow{3}{*}{ Van Wyk et al, 1997} & $\begin{array}{l}\text { Bruises, contusions, sprains, } \\
\text { fractures }\end{array}$ & $\begin{array}{l}\text { the body. It may be soaked in vinegar and used as an } \\
\text { external application to treat bruises, contusions, sprains }\end{array}$ \\
\hline & Cleans wounds & and fractures \\
\hline & & Used as an antiseptic to clean wounds \\
\hline
\end{tabular}


[4] Goldblatt P, Manning J. 2000. Cape Plants: A Conspectus of the Cape Flora of South Africa. National Botanical Institute of South Africa, Pretoria

[5] Van Wyk B-E, Gericke N. 2000. People's Plants. Briza Publications, Pretoria, South Africa

[6] Kaiser R, Lamparsky D, Schudel P. Analysis of buchu leaf oil. Journal of Agriculture and Food Chemistry 1975;23(5):943-950

[7] Fluck AAJ, Mitchel WM, Perry HM. Composition of Buchu Leaf Oil. Journal of the Science of Food and Agriculture 1961:290-292

[8] Van Wyk, B.-E. The potential of South African plants in the development of new medicinal products. South African Journal of Botany 2001;77:912-929

[9] Lis-Balchin M, Hart S, Simpson E. Buchu (Aganthosma betulina and A. Crenulata, Rutaceae) essential oils: their pharmacological action on guinea-pig ileum and antimicrobial activity on microorganisms. Journal of Pharmacy and Pharmacology 2001;53:579-592

[10] Grieve, M. 1937. A Modern Herbal. Jonathan Cape, London pp 133-134

[11] Diuretic diet pills http://dietpillshelp.com/diuretic-diet-pills/ Accessed 2 August 2013

[12] Moolla, A., Van Vuuren, S.F., Van Zyl, R.L., Viljoen, A.M. Biological activity and toxicity profile of 17 Agathosma (Ruataceae) species. South African Journal of Botany 2007;73:588-592

[13] Viljoen,A.M.,Moolla,A.,VanVuuren, S.F.,VanZyl, R.L., Başer, K.H.C., Demirci, B., Özek, T. The biological activity and essential oil composition of 17 Agathosma (Rutaceae) species. Journal of Essential Oil Research 2006;18: 2-16

[14] Cowan, M.M. Plant products as antimicrobial agents. Clinical Microbiology Reviews 1999;12:564-582

[15] Kothari S, Thompson A, Agarwal A, du Plessis SS. Free radicals: Their beneficial and detrimental effects on sperm maturation. Indian Journal of Experimental Biology 2010;48:425-435

[16] Yen, G.C., Hsieh, C.L. Anti-oxidant activity of extracts from Du-zhong (Eucommia ulmoides) toward various lipid peroxidation models in vitro. Journal of Agricultural and Food Chemistry 1998;46:3952-3957

[17] Ziada A, Rosenblum M, Crawford ED. Benign prostatic hyperplasia: an overview. Urology 1999; 53:1-6

[18] Eaton CL. Aetiology and pathogenesis of benign prostatic hyperplasia. Current opinion in urology 2003;13:7-10

[19] Bostanci Y, Kazzazi A, Momtahen S, Laze J, Djavan B. Correlation between benign prostatic hyperplasia and inflammation. Current Opinion in Urology 2013;23:5-10 
[20] Briganti A, Capitanio U, Suardi N et al. Benign prostatic hyperplasia and its aetiologies. European Urology Supplements 2009;8:865-871

[21] Ozayar A, Zumrutbas AE, Yaman O. The relationship between lower urinary tract symptoms (LUTS), diagnostic indicators of benign prostatic hyperplasia (BPH), and erectile dysfunction in patients with moderate to severely symptomatic BPH. International Urology and Nephrology 2009;40:933-939

[22] Sampson N, Madersbacher S, Berger P. Pathophysiology and therapy of benign prostatic hyperplasia. Wiener Klinische Wonchenschrift 2008;120(13-14):390-401

[23] Grayhack JT: Changes with aging in human seminal vesicle fluid fructose concentration and seminal vesicle weight. Journal of Urology 1961;86:142

[24] Vermeulen A, Kaufman JM, Goemaere S, van Pottelberg I. Estradiol in elderly men. Aging Male 2002;5:98-102

[25] Stettner M, Kaulfuss S, Burfeind P, et al. The relevance of estrogen receptor-beta expression to the antiproliferative effects observed with histone deacetylase inhibitors and phytoestrogens in prostate cancer treatment. Mol Cancer Ther 2007;6:2626-33

[26] Thomas JA, Keenan EJ. Effects of estrogens on the prostate. J Androl 1994;15:97-9

[27] Rittmaster RS, Fleshner NE, Thompson IM. Pharmacological approaches to reducing the risk of prostate cancer. Eur Urol 2009;55:1064-74

[28] Bonkhoff H, Berges R. The evolving role of oestrogens and their receptors in the development and progression of prostate cancer. Eur Urol 2009;55:533-42

[29] Gilleran JP, Putz O, DeJong M, et al. The role of prolactin in the prostatic inflammatory response to neonatal estrogen. Endocrinology 2003;144:2046-54

[30] Blaivas JG: Obstructive uropathy in the male. Urologic Clinics of North America 1996;23:373-384

[31] Kramer G, Marberger M. Could inflammation be a key component in the progression of benign prostatic hyperplasia? Current Opinion in Urology 2006;16:25-29

[32] Wang L, Yang JR, Yang LY, Liu ZT. Chronic inflammation in benign prostatic hyperplasia: implications for therapy. Medical Hypotheses 2008; 70:1021-1023

[33] Yoo TK, Cho HJ. Benign prostatic hyperplasia: from bench to clinic. Korean Journal of Urology 2012; 53:139-148

[34] Descazeaud A, Weinbreck N, Robert G, et al. Transforming growth factor beta-receptor II protein expression in benign prostatic hyperplasia is associated with prostate volume and inflammation. British Journal of urology International 2011; 108:E23-E28

[35] Bostwick DG, de la Roza G, Dundore P, Corica FA, Iczkowski KA. Intraepithelial and stromal lymphocytes in the normal human prostate. Prostate 2003;55:187-93 
[36] Agarwal A, Prabakaran C, Allamaneni S. What an andrologist/urologist should know about free radicals and why. Urology 2006;2:67

[37] Agarwal ACM, Abdelrarazik H, Sharma RK. Oxidative stress management iin patients with male or female factor infertility. Handbook of Chemiluminescent Methods in Oxidative Stress Assessment. 2008:195

[38] De Lamirande E, Jiang H, Zini A, Kodama H, Gagnon C. Reactive oxygen species and sperm physiology. Reviews of reproduction 1997;2:48

[39] Sikka SC. Relative impact of oxidative stress on male reproductive function. Current Medical Chemistry 2001;8:835

[40] Savas M. Oxidative Stress in Benign Prostate Hyperplasia. Oxidative stress in applied basic research and clinical practice 2012:591-615

[41] Manzoor A, Suhail N, Mansoor T, Banu N, Ahmad S. Evaluatuion of oxidative stress and DNA damage in Benign Prostatic Hyperplasia patients and comparison with controls. Indian Journal of Clinical Biochemistry 2012;4:385-388

[42] Mchedlidze MG, Shioshvili TI. Influence of antioxidants on the development of benign prostatic hyperplasia. Georgian medical news 2006;140:23-27

[43] Calò LA, Pagnin E, Davis PA, Lodde M, Mian C Semplicini A, Pycha A. Effect of doxazosin on oxidative stress-related proteins in benign prostatic hyperplasia. Urologica Internationalis 2006;76(1):36-41

[44] Steenkamp V, Gouws MC, Gulumian M, Elgorashi EE, van Staden J. Studies on antibacterial, anti-inflammatory and antioxidant activity of herbal remedies used in the treatment of benign prostatic hyperplasia and prostatitis. Journal of Ethnopharmacology 2006;103:71-75

[45] Ulleryd P. Febrile urinary tract infection in men. International Journal of Antimicrobial Agents 2003;22:S89-S93

[46] Blacklock NJ. The anatomy of the prostate: relationship with prostatic infection. Infection 1991;19(Suppl 3):S111-4

[47] Ronald AR. Current concepts in the management of urinary tract infections in adults. Medical Clinics of North America 984;68:335-49

[48] Schaeffer AJ. Urinary tract infection in men-state of the art. Infection 1994;22(Suppl 1):19-21

[49] Nicolle LE. A practical guide to antimicrobial management of complicated urinary tract infection. Drugs and Aging 2001;18:243-54

[50] Ulleryd P, Zackrisson B, Aus G, Bergdahl S, Hugosson J, Sandberg T. Selective urological evaluation in men with febrile urinary tract infection. British Journal of Urology International 2001;88:15-20 
[51] Ozayar A, Zumrutbas AE, Yaman O. The relationship between lower urinary tract symptoms (LUTS), diagnostic indicators of benign prostatic hyperplasia (BPH), and erectile dysfunction in patients with moderate to severely symptomatic BPH. International Urology and Nephrology 2009;40:933-939

[52] DiPasquale R. Effective use of herbal medicine in urinary tract infections. Journal of Dietary Supplements, 2009;5(3):219-229

[53] Al-Bayati, FA. Synergistic antibacterial activity between Thymus valgaris and Pimpinella anisum essential oils and methanol extreacts. Journal of Ethnopharmacology 2008;116:403-406

[54] Gatie M, Gebre-Mariama T, Rietz R, Hohne C, Huschkad C, MSchmidtkee M, Abetaf a, Neuberb RHH. Evaluation of the anti-microbial and anti-inflammatory activities of the medicinal plants Dodonaea viscose, Rumex nervosus and Rumex abyssinicus. Fitoterapia 2003;74:139-143

[55] Patel M, Coogan MM. Antifungal activity of the plant Dodonaea viscose var. Angustifolia on candida albicans from HIV-infected patients. Journal of Ethnopharmacology 2008;139:81-89

[56] Tremellen K. Oxidative stress and male fertility - a clinical perspective. Human Reproduction Update 2008;14:243

[57] Blake DR, Allen RE, Lunec J. Free radicals in biological systems - a review orientated to inflammatory processes. British medical Bulletin 1987;43:371

[58] Wolff H, Politch JA, Martinez A, et al. Leukocytospermia is associated with poor semen quality. Fertility and Sterility 1990;53:528

[59] Maruyama DK Jr, Hale RW, Rogers BJ. Effects of white blood cells on the in vitro penetration of the zona-free hamster eggs by human spermatozoa. Journal of Andrology $1985 ; 6: 127$

[60] Koch OR, Pani G, Borello S et al. Oxidative stress and antioxidant defences in ethanol-induced cell injury. Molecular Aspects of Medicine 2004;25:191

[61] Padron OF, Bracket NL, Sharma RK et al. Seminal reactive oxygen species and sperm motility and morphology in men with spinal cord injury. Fertility and Sterility $1997 ; 67: 1115$

[62] de Lamirande E, Leduc BE, Iwasaki A, Hassouna M, Gagnon C. Increased reactive oxygen species formation in semen of patients with spinal cord injury. Fertility and Sterility 1995;63:637

[63] Mitropoulos D, Deloconstantinos G, Zervas A et al. Nitric oxide synthase and xanthine oxidase activates in the spermatic vein of patients with varicocoele: a potential role for nitric oxide in sperm dysfunction. Journal of Urology 1996;156:1952 
[64] Mehraban D, Ansari M, Keyhan H et al. Comparison of nitric oxide concentration in seminal fluid between infertile patients with and without varicocoel and normal fertile men. Urology Journal 2005;2:106

[65] O’Flaherty C, de Lamirande E, Gagnon C. Positive role of reactive oxygen species in mammalian sperm capacitation: triggering and modulation of phosphorylation events. Free Radical Biology and Medicine 2006;41:528

[66] Aitken RJ. The cell biology of fertilization. Advances in Experimental Medicine and Biology 1997;424:291

[67] Agarwal A. Oxidative stress and human reproduction. Oxidative Stress, Disease and Cancer. Roswell Park Cancer Institute (New York) 2006:687

[68] Sikka SC, Rajasekaran M, Hellstrom WJ. Role of oxidative stress and antioxidants in male fertility. Journal of Andrology 1995;16:464

[69] Twigg J, Irvine DS, Houston P et al. Iatrogenic DNA damage induced in human spermatozoa during sperm preparation: protective significance of seminal plasma. Molecular Human Reproduction 1998;4:439

[70] Sawyer DE, Mercer BG, Wiklendt AM, Aitken RJ. Quantitative analysis of gene-specific DNA damage in human spermatozoa. Mutation Research 2003;529:21

[71] Agarwal A, Said TM. Oxidative stress, DNA damage and apoptosis in male fertility: a clinical approach. British Journal of Urology International 2005;95:503

[72] Amiri I, Sheikh N, Najafi R. Nitric oxide level in seminal plasma and its relation with sperm DNA damages. Iranian Biomedical Journal 2007;11:259

[73] Irvine DS, Twigg JP, Gorman EL et al. DNA integrity in human spermatozoa: relationships with semen quality. Journal of Andrology 200;21:33

[74] Cocuzza M, Sikka SC, Athayde KS, Agarwal A. Clinical relevance of oxidative stress and sperm chromatin damage in male fertility: an evidence based analysis. International Brazilian Journal of Urology 2007;33:603

[75] Sakkas D, Marierhoz E, Manicardi G et al. Origin of DNA damage in ejaculated human spermatozoa. Reviews of Reproduction 1999;4:31

[76] Agarwal A, Makker K, Sharma R. Clinical relevance of oxidative stress in male factor fertility: an update. American Journal of Reproductive Immunology 2008;59:2

[77] Wang X, Sharma RK, Sikka SC et al. Oxidative stress is associated with increased apoptosis leading to spermatozoa DNA damage in patients with male factor fertility. Fertility and Sterility 2003;80:531

[78] Said TM, Paasch U, Glander HJ, Agarwal A. Role of caspases in male infertility. Human Reproduction Update 2004;10:39 
[79] Ishii T, Matsuki S, Iuchi Y et al. Accelerated impairment of spermatogenic cells in SOD1-knockout mice under heat stress. Free Radical Research 2005;39:697

[80] Bajpayee P, Kumar K, Sharma et al. Prostatitis: Prevalence, health impacts and quality improvement strategies. Acta Poloniae Pharmaceutica 2012;69(4):571-579 